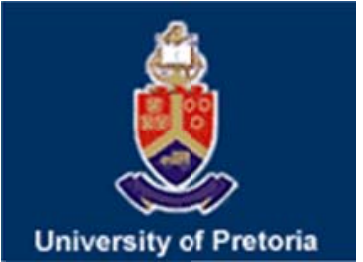

University of Pretoria Department of Economics Working Paper Series

\title{
Monetary Policy and Bubbles in US REITs
}

Petre Caraiani

Institute for Economic Forecasting

Adrian Cantemir Călin

Institute for Economic Forecasting

Rangan Gupta

University of Pretoria

Working Paper: 2018-45

July 2018

Department of Economics

University of Pretoria

0002, Pretoria

South Africa

Tel: +27 124202413 


\title{
Monetary Policy and Bubbles in US REITs
}

\author{
Petre Caraiani* \\ Institute for Economic Forecasting, Romanian Academy \\ Adrian Cantemir Călin \\ Institute for Economic Forecasting, Romanian Academy \\ Calea 13 Septembrie no. 13, Casa Academiei, Bucharest, Romania \\ Rangan Gupta \\ University of Pretoria, Department of Economics \\ Pretoria 0002, South Africa
}

\begin{abstract}
In this paper, we analyze the effects of monetary policy on the bubbles in the Real Estate Investment Trusts (REITs) sector of the United States. We use a time-varying vector autoregressive (VAR) model over the quarterly period of 1972:1 to 2018:1. We find protracted periods, starting from the onset of the recent financial crisis to the end of the sample period, where contractionary monetary policy is associated with increases in the bubble component in the REITs of the US economy. This result, which is robust to alternative REITs indexes, is contrary to the "conventional" view, as well as to the predictions of standard models of bubbles.
\end{abstract}

Keywords: REITs, Bubbles, VAR, Monetary Policy

*Corresponding author

Email addresses: caraiani@ipe.ro (Petre Caraiani), cantemircalin@gmail.com (Adrian Cantemir Călin), Rangan.Gupta@up.ac.za (Rangan Gupta) 


\section{Introduction}

The root of the global economic and financial crisis of 2008-2009 is commonly associated with the rapid decline in real estate prices, following a prolonged boom. Since there exists a large literature on the impact of monetary policy on general real estate prices and vice versa (see for example, Del Negro and Otrok (2007), Bjørnland and Jacobsen (2010), Bjørnland and Jacobsen (2013), Rahal (2016), Simo-Kengne, Miller, Gupta, and Balcilar (2016), Marfatia, Gupta, and Cakan (2017)), Huber and Punzi (2018), Plakandaras, Gupta, Katrakilidis, and Wohar (2018), it is not surprising that there is now a revived interest in the long standing debate on whether and how monetary policy should respond to perceived deviations of real prices from fundamentals. Given the beliefs that asset price bubbles are difficult to detect and measure, and that interest rates are a blunt instrument to prick a bubble resulting in unintended collateral damages, the consensus view is that central banks should focus on stabilizing inflation and the output gap only (Bernanke and Gertler (1999); Bernanke and Gertler (2001); Kohn (2006)). The recent crisis has, however, challenged this consensus and strengthened the viewpoint that monetary authorities should raise the interest rate to counteract asset price bubbles, even at the cost of temporarily deviating from their (inflation or output gap) targets, since any losses associated with such deviations would be more than offset by the avoidance of the consequences of a future burst of the bubble (this has come to be known as "leaning against the wind").

A central assumption of the case for the above "leaning against the wind" monetary policy is the belief that an increase in interest rates will reduce the size of an asset price bubble. Barring the cases of Gali and Gambetti (2015) and Caraiani and Calin (2018), who analyze the impact of monetary policy on stock market bubbles, and find empirical evidences contradicting this view ${ }^{1}$ to the best of our knowledge, no empirical testing of the same has

\footnotetext{
1 Caraiani and Calin (2018) revisited the results in Gali and Gambetti (2015) by reestimating their time-varying vector autoregressive (TVP-VAR) model, including a measure of shadow rate instead of the Federal funds rate to capture monetary policy during the zero lower bound. These authors, when looking at the results during and in the aftermath of the crisis, found that, with the shadow rate, the impact of monetary policy shocks on asset prices became negative, unlike Gali and Gambetti (2015)'s observation of protracted episodes in which stock prices end up increasing persistently in response to an exogenous tightening of monetary policy. In addition, Caraiani and Calin (2018) also detected a much lower positive impact of monetary policy shocks on bubbles, when using the shadow rate.
} 
been conducted for real estate markets. This we find quite baffling, given that the recent global crisis originated from the burst of the bubble in the real estate market of the US.2

Against this backdrop, following Gali and Gambetti (2015) and Caraiani and Calin (2018), we provide evidence on the dynamic time-varying response of Real Estate Investment Trusts (REITs) prices ${ }^{3}$ to monetary policy shocks using a time-varying vector autoregressive (TVP-VAR) model $[4$ and try to use that evidence to infer the nature of the impact of interest rate changes on the (possible) bubble component of REITs prices. Based on a TVP-VAR comprising of quarterly data (on measures of output, general and commodity prices, dividends, interest rate and REITs), over the period of 1972:1 to 2018:1, our goal is to assess the empirical merits of the "conventional" view, which predicts that the size of the bubble component of REITs prices should decline in response to an exogenous increase in interest rates. Since the fundamental component is expected to go down in response to the same policy intervention, any evidence pointing to a positive response of observed (sum of the fundamental and bubble components) REITs prices to an exogenous interest rate hike would call into question the conventional view regarding the effects of monetary policy on REITs price bubbles. The remainder of the paper is organized as follows: In Section 2 we provide the theoretical and empirical frameworks, while Section 3 lays data and the results, with Section 4 concluding the paper.

\section{Theoretical and Empirical Frameworks}

The following section is dedicated to the theoretical model employed in order to identify the impact of monetary policy shocks on asset prices and

\footnotetext{
${ }^{2}$ For detailed discussions on detection of bubbles in US REITs, see for example, Anderson, Brooks, , and Tsolacos (2011), Nneji, Brooks, , and Ward (2013), Escobari and Jafarinejad (2016), and Pavlidis, Yusupova, Paya, Peel, Martinez-Garcia, Mack, and Gross$\operatorname{man}(2016)$ for bubbles in international housing markets.

'The decision to use REITs prices instead of housing prices, in this paper at this stage, is primarily because of the fact that, unlike the REITs price index, which is homogenous across the country, housing markets are regional in nature, with tremendous heterogeneity in terms of their response to monetary policy (Gupta and Kabundi (2010); Gupta, Jurgilas, Kabundi, and Miller (2012a); Gupta, Miller, and van Wyk (2012b).

${ }^{4}$ The TVP-VAR model, not only allows us to accommodate for structural changes, but also model empirically the fact that the overall effect on the observed stock price may change over time as the relative size of the bubble changes, since changes in interest rates have a different impact on the fundamental and bubble components.
} 
asset price bubbles. In addition to the theoretical construct, the section also documents on the VAR approach used.

\subsection{A Theoretical Framework for Analysis}

We start from the partial equilibrium asset pricing model introduced by Gali and Gambetti (2015), which is devised for an economy populated by risk neutral investors, where $R_{t}$ stands for the riskless real interest rate, $Q_{t}$ denotes prices at time $t$ and $D_{t}$ represents the dividend stream. We treat the prices at any moment as a sum between a "fundamental" component and a "bubble" component, as shown in the following equation.

$$
Q_{t}=Q_{t}^{F}+Q_{t}^{B}
$$

We next consider that the fundamental component of the above expression is given by the present discounted value of future dividends, as reflected by Equation 2. This in turn can be expressed in log-linear form as in Equation 3.

$$
\begin{gathered}
Q_{t}^{F}=E_{t}\left\{\sum_{k=1}^{\infty}\left(\prod_{j=0}^{k-1} \frac{1}{R_{t+j}}\right) D_{t+k}\right\} \\
q_{t}^{F}=c+\sum_{k=0}^{\infty} \lambda^{k}\left[(1-\lambda) E_{t}\left\{d_{t+k+1}\right\}-E_{t}\left\{r_{t+k}\right\}\right]
\end{gathered}
$$

In the above context, $c$ is a constant and $\lambda=\frac{\Gamma}{R}$. $\Gamma$ and $R$ represent the growth rates for the dividend and interest rate. In this setup, we assume that the responses of the two components described above to an exogenous shock $\epsilon_{t}^{m}$ will yield the impact of interest rate shocks on asset prices and bubbles. Therefore, we differentiate Equation 3 with respect to the exogenous shock and obtain:

$$
\frac{\partial q_{t+k}}{\partial \epsilon_{t}^{m}}=\left(1-\gamma_{t-1}\right) \frac{\partial q_{t+k}^{F}}{\partial \epsilon_{t}^{m}}+\gamma_{t-1} \frac{\partial q_{t+k}^{B}}{\partial \epsilon_{t}^{m}}
$$

We consider that $\gamma_{t}=Q_{t}^{B} / Q_{t}$ shows the fraction of the bubble component in a certain price, at time $t$. Using this specification and Equation 2 , we can assert that the response of the fundamental component can be formally expressed as:

$$
\frac{\partial q_{t+k}^{F}}{\partial \epsilon_{t}^{m}}=\sum_{j=0}^{\infty} \lambda^{j}\left((1-\lambda) \frac{\partial d_{t+k+j+1}}{\partial \epsilon_{t}^{m}}+\frac{\partial r_{t+k+j}}{\partial \epsilon_{t}^{m}}\right)
$$


Gali and Gambetti (2015) note that both standard economic reasoning and the associated empirical literature consider a contraction of the fundamental component as a result of a rise in the real interest rate such that: $\frac{\partial q_{t+k}^{F}}{\partial \epsilon_{t}^{m}} \leq 0$. Moreover, the same effect is expected also for the bubble component, and therefore: $\frac{\partial q_{t+k}^{B}}{\partial \epsilon_{t}^{m}} \leq 0$. In this light, the aggregate impact on a certain asset price should be negative:

$$
\frac{\partial q_{t+k}}{\partial \epsilon_{t}^{m}} \leq 0
$$

Gali and Gambetti (2015) revisit the arguments found in Gali (2014) and point out the fact that the hypothesis of a negative reaction of a bubble to interest rate expansions lacks theoretical support and falls on the opposite spectrum of normal intuition. In order to explore this, we assume that Equation 7 holds in a rational expectations equilibrium, and that the expression of the fundamental component (Equation 2) satisfies Equation 8.

$$
\begin{gathered}
Q_{t} R_{t}=E_{t}\left\{D_{t+1}+Q_{t+1}\right\} \\
Q_{t}^{F} R_{t}=E_{t}\left\{D_{t+1}+Q_{t+1}^{F}\right\}
\end{gathered}
$$

By considering Equation 1 in conjunction with the last two equations, we can rapidly confirm that the bubble component satisfies the following expression:

$$
Q_{t}^{B} R_{t}=E_{t}\left\{Q_{t+1}^{B}\right\}
$$

In log-linear form, Equation 9 becomes:

$$
E\left\{\Delta q_{t+1}^{b}\right\}=r_{t}
$$

Therefore, a hike in the interest rate will be translated into an escalation of the bubble component, which falls against mainstream considerations on the linkages between interest rates and bubbles. Moreover, Gali and Gambetti (2015) assert that interest rates could also influence bubbles through a comovement channel, and in order to expand this logic we consider the above expression at $t-1$ while discarding the expectation operator.

$$
\Delta q_{t}^{b}=r_{t-1}+\epsilon_{t}
$$

In Equation 11, $\xi_{t}=q_{t}^{B}-E_{t-1} q_{t}^{B}$ is an arbitrary process that satisfies the martingale-difference feature. Gali and Gambetti (2015) also note 
that the innovation in bubble magnitude $\xi_{t}$, is not necessarily connected to fundamentals or interest rate dynamics and therefore:

$$
\xi_{t}=\psi_{t}\left(r_{t}-E_{t-1}\left[\left(r_{t}\right)\right]\right)+\xi_{t}^{*}
$$

In the above set-up, $\psi_{t}$ is a random parameter without theoretical restrictions in terms of sign, size or dependence on policy regime. Hence, the reaction of the bubble component to monetary shocks is formulated as:

$$
\frac{\partial q_{t+k}^{B}}{\partial \epsilon_{t}^{m}}= \begin{cases}\psi_{t} \frac{\partial r_{t}}{\partial \epsilon_{t}^{m}}, & \text { for } k=0 \\ \psi_{t} \frac{\partial r_{t}}{\partial \epsilon_{t}^{m}}+\sum_{j=0}^{k-1} \frac{\partial r_{t+j}}{\partial \epsilon_{t}^{m}}, & \text { for } k=1,2, \ldots\end{cases}
$$

As specified by Gali and Gambetti (2015) although the initial reaction given by $\psi_{t}$ is indeterminate, the long run influence of monetary policy shocks on bubble magnitude will be either positive or negative, should the dimension of the real interest rate response be large enough to offset any initial impact.

\subsection{A Bayesian Time-Varying VAR Approach}

We model the impact of monetary policy shocks on bubbles through the use of a time-varying Bayesian VAR approach which is inspired by the earlier specifications of Primiceri (2005). Following in the footsteps of Gali and Gambetti (2015) we also adopt the identification scheme developed by Christiano, Eichenbaum, and Evans (2005). Formally, the model can be expressed in the following way:

The following time-varying specification is used for the autoregressive model:

$$
x_{t}=A_{0, t}+A_{1, t} x_{t-1}+\ldots+A_{p, t} x_{t-p}+u_{t}
$$

In Equation 14, $A_{0, t}$ represents a vector of time-varying intercepts and the $A_{i, t}$ matrices quarter the time-varying coefficients. Moreover, the innovation vector $u_{t}$ follows a zero mean and $\Sigma_{t}$ covariance matrix white noise Gaussian process. We consider that the above mentioned innovations are linear transformations of the structural shocks, such that: $E\left\{\epsilon_{t} \epsilon_{t}^{\prime}\right\}=I$, $E\left\{\epsilon_{t} \epsilon_{t-k}^{\prime}\right\}=0$ and also $S_{t} S_{t}^{\prime}=\Sigma_{t}$.

\section{Empirical Analysis}

\subsection{Data}

Our Bayesian VAR model relies on seven US variables, observed at quarterly frequency over the period of 1972:1 to 2018:1, following the specification 
introduced by Gali and Gambetti (2015). The macroeconomic variables used are real GDP, the GDP deflator and the effective Federal funds rate. These variables have been obtained from FRED database of the Federal Reserve Bank of St. Louis. However, as suggested by Caraiani and Calin (2018), given the zero lower bound situation of the monetary policy instrument in the wake of the "Great Recession", we use the shadow short rate developed by $\mathrm{Wu}$ and Xia (2016) between 2009:1 to 2015:4. Note that, the shadow short rate is the nominal interest rate that would prevail in the absence of its effective lower bound, with it derived by modelling the (three-factors) term structure of the yield curve, and has been shown by $\mathrm{Wu}$ and Xia (2016) to be a close approximation of the effective Federal funds rate during the conventional periods of monetary policy decision-making. Secondly, we incorporate a non-energy commodity price index acquired from the World Bank. Finally, we utilize total returns index and dividends for the FTSE Nareit U.S. REITs. While we focus on the All REITs5 index in the main text, robustness analyses are presented in the Appendix for Composite ${ }^{6}$ All Equity $]^{7}$ Equity ${ }^{8}$ and Mortgag $\AA^{9}$ REITs indices, considered in turn. The data on the various REITs and corresponding dividends are derived from the official website of Nareit (www.reit.com).

\subsection{Bayesian VAR Model}

The econometric framework is based on the reference time-varying Bayesian VAR due to Primiceri (2005). Following Gali and Gambetti (2015), we identify the monetary policy shocks using the econometric approach outlined by Christiano et al. (2005).

To summarize once again the data series used, we employ the following series: $y_{t}, p_{t}, p_{t}^{e}, i_{t}, q_{t}, d_{t}$, standing for, respectively log of output, log of the

\footnotetext{
${ }^{5}$ This is a market capitalization-weighted index that and includes all tax-qualified real estate investment trusts (REITs) that are listed on the New York Stock Exchange, the American Stock Exchange or the NASDAQ National Market List.

${ }^{6}$ This is a free-float adjusted, market capitalization-weighted index of U.S. Equity and Mortgage REITs.

${ }^{7}$ This is a free-float adjusted, market capitalization-weighted index of U.S. equity REITs. Constituents of the index include all tax-qualified REITs with more than 50 percent of total assets in qualifying real estate assets other than mortgages secured by real property.

${ }^{8}$ This index contains All Equity REITs not designated as Timber REITs or Infrastructure REITs.

${ }^{9}$ This is a free-float adjusted, market capitalization-weighted index including all taxqualified REITs with more than 50 percent of total assets invested in mortgage loans or mortgage-backed securities secured by interests in real property.
} 
price level, the log of commodity prices index, the central bank's interest rate, $\log$ of the REITs index, as well as the corresponding log of the dividend series (both in real terms). The following vector of endogenous variables is employed: $x=\left[\Delta y_{t}, \Delta d_{t}, \Delta p_{t}, \Delta p_{t}^{e}, i_{t}, \Delta d_{t}\right]$.

The equation summarizing the vector is given in Eq. 15. We also can write $\theta_{t}=\operatorname{vec}\left(A_{t}^{\prime}\right)$ with $A_{t}=\left[A_{0, t}, A_{1, t}, \ldots, A_{p, t}\right]$, where $\operatorname{vec}()$ denotes the column stacking operator. We use the following process for $\theta_{t}$ :

$$
\theta_{t}=\theta_{t-1}+\omega_{t}
$$

Here $\omega_{t}$ denotes a Gaussian process characterized by a zero mean and a constant covariance $\Omega$.

We decompose the time-varying covariance matrix $\Sigma_{t}$ in $\Sigma_{t}=F_{t} D_{t} F_{t}^{\prime}$. Here, $F_{t}$ is lower-triangular with a main diagonal consisting of ones, while $D_{t}$ is a diagonal matrix. The vector $\sigma_{t}$ is characterized by diagonal elements of $D_{t}^{1 / 2}$, and by $\phi_{i, t}$ the column vector. The latter has nonzero elements of the row $(i+1)$ of $F_{t}^{-1}$ for $i=1, . ., 5$. We further assume that:

$$
\begin{array}{r}
\log \sigma_{t}=\log \sigma_{t-1}+\zeta_{t} \\
\phi_{i, t}=\phi_{i, t-1}+\nu_{i, t}
\end{array}
$$

Furthermore, we consider that the innovations $\zeta_{t}, \nu_{t}$ are assumed to follow a Gaussian process characterized by a zero mean and a constant covariances denoted by $\Xi$ and by $\Psi_{i}$.

A key issue here with respect to the main results pertains to the identification of monetary policy shocks. We mentioned that we follow Gali and Gambetti (2015) who used the identification scheme of Christiano et al. (2005). The main ingredient here is the assumptions that the monetary policy shocks do not affect contemporaneously the GDP, the dividends or the inflation and that the central bank interest rates do not respond immediately (contemporaneously) to changes in REITs prices.

\subsubsection{Time-Varying Impulse Responses}

Our focus here is on the changing responses of the ALL REITs index, and the associated behavior of the bubble component of the same, following the contractionary monetary policy shock, displayed in Figures 1-310 As

\footnotetext{
${ }^{10}$ The responses of all the other variables in the TVP-VAR are qualitatively similar to those in Gali and Gambetti (2015) and Caraiani and Calin (2018), and are available upon request from the authors.
} 
observed from Figure 1, the ALL REITs returns tend to decline in general on impact and over the various horizons over the entire sample period considered. The only exception is at longer horizons, at the early part of the sample period. In Figure 2, we present the response of the gap between the observed and the fundamental values (underlying dividends) of the ALL REITs index. With the exception of the early part of the sample and the period during- and post- the financial crisis, the contractionary monetary policy reduces the bubble component, i.e., the result for the bulk of the sample period is in line with the "conventional" view. However, the dynamics observed for the extreme ends of the sample, where the responses of the bubbles are found to be positive and growing is consistent with the theory of rational bubbles as outlined by Gali (2014) or Gali and Gambetti (2015). Figure 3 shows the estimated (bootstrap-based) probability that the gap between observed and fundamental REITs index is positive. As observed in Figure 2, the probability is well above 50 percent (and often close to unity on impact of the monetary shock) at the early part and from the onset of the financial crisis until the end of the sample period (barring at the 3-years-ahead horizon) - a result in line with Gali and Gambetti (2015).

As a robustness check, we re-conducted the above analysis using Composite, All Equity, Equity, and Mortgage REITs indexes, instead of the ALL REITs index. In Figures 4-7, we present the estimated (bootstrap-based) probability that the gap between the observed and fundamental REITs index is positive following a contractionary monetary policy shock for the Composite, All Equity, Equity, and Mortgage REITs indices, respectively. As can be seen from these figures, the results are qualitatively comparable with those reported for the ALL REITs index in Figure 3. In other words, the probability is generally high at the early part of the sample, and from the beginning of the financial crisis till the end of our sample period.

\section{Conclusions}

The "conventional" view of monetary policy suggests that the size of the bubble component of asset prices should decline in response to an exogenous increase in interest rates. Realizing the role played by the real estate sector in the "Great Recession", we use a a vector autoregressive model with timevarying coefficients to analyze the impact of monetary policy shocks on US REITs over the quarterly period of 1972:1 to 2018:1. Using an identification scheme which assumes no contemporaneous response of monetary policy to REITs prices, the evidence points to protracted periods, starting from the onset of the recent financial crisis to the end of the sample period, 
where contractionary monetary policy is associated with increases in the bubble component in the REITs of the US economy. In other words, this result, which is robust to alternative REITs indices, is at odds with the "conventional" view, as well as with the predictions of standard bubble models. In sum, proposals for a "leaning against the wind" monetary policy in response to perceived deviations of asset prices from fundamentals, which in turn, rely on the assumption that increases in interest rates will succeed in shrinking the size of an emerging asset price bubble, are not supported by our study, especially in the period associated with the recent global financial crisis and thereafter. 


\section{References}

Anderson, K., Brooks, C., , Tsolacos, S., 2011. Testing for Periodically Collapsing Rational Speculative Bubbles in US REITs. Journal of Real Estate Portfolio Management 17 (3), 227-241.

Bernanke, B. S., Gertler, M., 1999. Monetary Policy and Asset Price Volatility. New Challenges for Monetary Policy, Federal Reserve Bank of Kansas City, 77-128.

Bernanke, B. S., Gertler, M., 2001. Should Central Banks Respond to Movements in Asset Prices? American Economic Review 91 (2), 253-257.

Bjørnland, H., Jacobsen, D., 2010. The Role of House Prices in the Monetary Policy Transmission Mechanism in Small Open Economies. Journal of Financial Stability 6 (4), 218-229.

Bjørnland, H., Jacobsen, D., 2013. House Prices and Stock Prices: Different Roles in the U.S. Monetary Transmission Mechanism. Scandinavian Journal of Economics 115 (4), 1084-1106.

Caraiani, P., Calin, A. C., 2018. The effects of monetary policy on stock market bubbles at zero lower bound: Revisiting the evidence. Economics Letters.

Christiano, L. J., Eichenbaum, M., Evans, C. L., 2005. Nominal Rigidities and the Dynamic Effects of a Shock to Monetary Policy. Journal of Political Economy 113 (1), 1-45.

Del Negro, M., Otrok, C., 2007. 99 Luftballons: Monetary Policy and the House Price Boom Across U.S. States. Journal of Monetary Economics 54, 1962-1985.

Escobari, D., Jafarinejad, M., 2016. Date Stamping Bubbles in Real Estate Investment Trusts. The Quarterly Review of Economics and Finance 60, $224-230$.

Gali, J., 2014. Monetary policy and rational asset price bubbles. American Economic Review 104 (3), 721-52.

Gali, J., Gambetti, L., 2015. The effects of monetary policy on stock market bubbles: Some evidence. American Economic Journal: Macroeconomics 7 (1), 233-57. 
Gupta, R., Jurgilas, M., Kabundi, A., Miller, S. M., 2012a. Monetary Policy and Housing Sector Dynamics in a Large-Scale Bayesian Vector Autoregressive Model. International Journal of Strategic Property Management 16 (1), 1-20.

Gupta, R., Kabundi, A., 2010. The effect of monetary policy on house price inflation: A factor augmented vector autoregression (favar) approach. Journal of Economic Studies 37 (6), 616-626.

Gupta, R., Miller, S. M., van Wyk, D., 2012b. Financial Market Liberalization, Monetary Policy, and Housing Price Dynamics. International Business \& Economics Research Journal 11 (1), 69-82.

Huber, F., Punzi, M. T., 2018. International Housing Markets, Unconventional Monetary Policy and the Zero Lower Bound. Macroeconomic Dynamics, Forthcoming.

Kohn, D. L., 2006. Monetary Policy and Asset Prices. Speech at an ECB colloquium on "Monetary Policy: A Journey from Theory to Practice," held in honor of Otmar Issing.

Marfatia, H. A., Gupta, R., Cakan, E., 2017. The International REITs TimeVarying Response to the U.S. Monetary Policy and Macroeconomic Surprises. North American Journal of Economics and Finance 42 (1), 640-653.

Nneji, O., Brooks, C., , Ward, C., 2013. Commercial Real Estate and Equity Market Bubbles: Are they Contagious to REITs? Urban Studies 50 (12), $2496-2516$.

Pavlidis, E., Yusupova, A., Paya, I., Peel, D., Martinez-Garcia, E., Mack, A., Grossman, V., 2016. Episodes of Exuberance in Housing Markets: In Search of the Smoking Gun. Journal of Real Estate Finance and Economics 53 (4), 419-449.

Plakandaras, V., Gupta, R., Katrakilidis, C., Wohar, M. E., 2018. TimeVarying Role of Macroeconomic Shocks on House Prices in the US and UK: Evidence from Over 150 Years of Data. Empirical Economics, Forthcoming.

Primiceri, G. E., 2005. Time varying structural vector autoregressions and monetary policy. The Review of Economic Studies 72 (3), 821-852.

Rahal, C., 2016. Housing Markets and Unconventional Monetary Policy. Journal of Housing Economics 32, 67-80. 
Simo-Kengne, B. D., Miller, S. M., Gupta, R., Balcilar, M., 2016. Evolution of the Monetary Transmission Mechanism in the US: The Role of Asset Returns. The Journal of Real Estate Finance and Economics 52 (3), 226243.

Wu, J. C., Xia, F. D., 2016. Measuring the macroeconomic impact of monetary policy at the zero lower bound. Journal of Money, Credit and Banking 48 (2-3), 253-291. 
The Impact of Monetary Policy Shocks on Bubbles Using ALL REITs Index

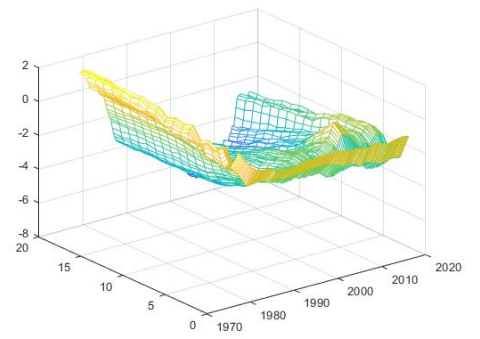

Figure 1: ALL REITs Index Response

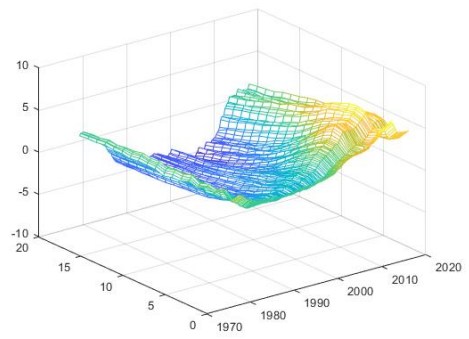

Figure 2: Bubble Response of ALL REITs Index

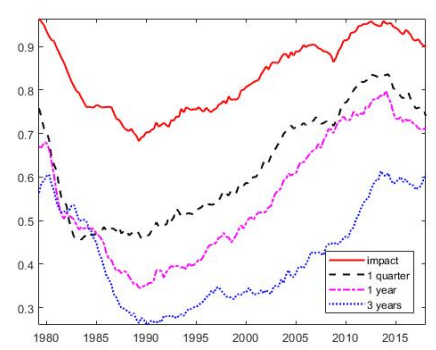

Figure 3: Probability of a Positive Response in All REITs Index 
The Impact of Monetary Policy Shocks on Bubbles Using Alternative REITs Indices

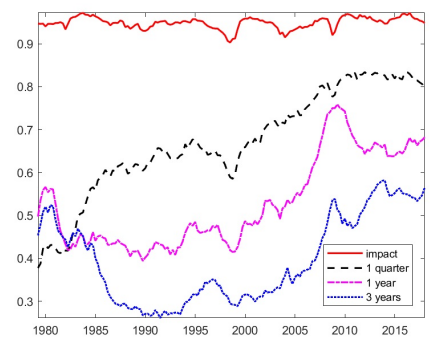

Figure 4: Probability of a Positive Response of Bubbles in All Equity REITs Index

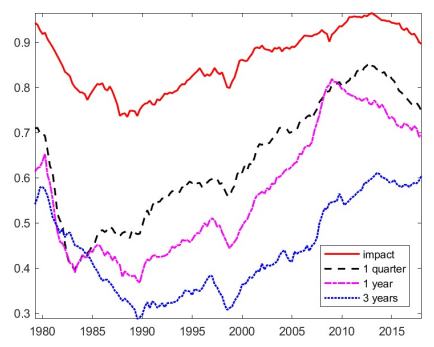

Figure 5: Probability of a Positive Response of Bubbles in Composite REITs Index

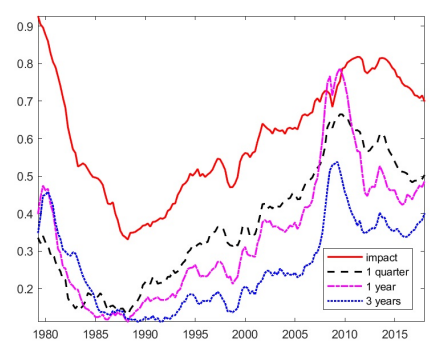

Figure 6: Probability of a Positive Response of Bubbles in Equity REITs Index 


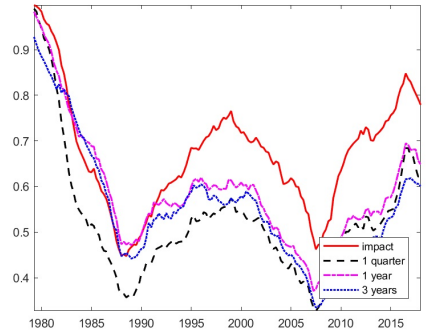

Figure 7: Probability of a Positive Response of Bubbles in Mortgage REITs Index 